|Volume 6 |Number 2 |December 2021 |E-ISSN: 2503-4405 |P-ISSN: 2580-3441|

\title{
How did Students Perceive Classroom Learning under Strict COVID-19 Pandemic Closures and Restrictions?
}

\author{
Takayoshi Sako \\ Senior High School Attached to Kyoto University of Education, Japan \\ tsako@kyokyo-u.ac.jp
}

\begin{abstract}
The COVID-19 pandemic of 2020 required strict infection prevention measures worldwide, including school closure. After school reopened, we implemented Japan's strict COVID measures, under which close contact in pairs or groups, as well as vocalizing in unison, was proscribed, with students having to remain quiet and face the blackboard.

This study's aim is to answer the question of how students felt about learning under such extreme constraints. One of the most noticeable findings from the responses to the survey of the 2020 class was that they felt the lack of collaborative learning experiences; hence, in 2021, we implemented changes that would allow for more collaboration while still adhering to COVID prevention guidelines. Among the various collaborative learning activities in the classroom, students reported that they found value in debate activities that challenged their English language skills and critical thinking. Overall, however, students found comfort and value in a semblance of learning with their peers.

It was concluded that even in a volatile and uncertain situation, such as a pandemic, it is crucial to improve environments for collaborative learning. In the future, quantitative study of the impact of collaborative learning on students' English proficiency will be a useful follow-up study.
\end{abstract}

Keywords: action research, collaborative learning, COVID-19 pandemic, school closure, sense of community

\section{INTRODUCTION}

\section{Unprecedented School Closures under a Pandemic}

The global spread of a new coronavirus infection (pandemic) in 2020 ushered in what can only be called a turbulent era. Myung and Kimner (2020) used the concept of volatility, uncertainty, complexity, ambiguity (VUCA), which originated in the US military, to describe such turbulent circumstances. On February 28, 2020, in response to the spread of the new coronavirus, the Japanese government requested all public schools in the country to close temporarily, plunging the education field into chaos. Closing all the 
schools at once was a massive undertaking that triggered a VUCA environment in the field of education of unprecedented proportions, and it provided an opportunity to reexamine the significance of education in Japan and revisit its traditions.

\section{The Impact of the School Closures on Classroom Learning}

I work at a high school affiliated with a national university. Here I summarize the changes in classroom guidelines at our school triggered by the COVID-19 shutdowns. At a staff meeting held on April 2, 2020, the vice-principal announced that when schools reopened, "activities involving simultaneous vocalization by all students" and "group and pair work conducted at close range, especially activities involving consultation among students" would be prohibited. At the May 22 staff meeting, just before the reopening, the school added that all students would have to sit facing the blackboard and would not be allowed to move their seats, as well as adding provisions on classroom seating arrangements and mandatory ventilation.

The most challenging aspect was the loss of the first three months to build rapport with the students. Our teaching experience had already taught us that the early part of the school year can be critical for a classroom's success or failure the rest of the year; during this period, we grasped our students' characteristics and academic abilities, and of the class as a whole, and we made subtle adjustments to the lesson designs. In 2020, the loss of those few months to build trust and discipline was undoubtedly a major blow to our subsequent classroom management.

\section{Possibilities and Limitations of Online Learning}

These pandemic-related school closures were not a phenomenon unique to Japan but became a global issue, devastating the education sector. More than 1.6 billion students worldwide have been affected by school closures, and as of January 2021, UNESCO estimates that more than 234 million children and adolescents in 33 countries have been affected by school closures (US Agency for International Development, 2021). Stakeholders have come to view online teaching and learning as a unique remedy. To help institutions overcome this unexpected crisis, UNESCO has been working with ministries of education across nations to ensure continued learning of students using different alternative channels and supporting them in various ways by technical assistance, selection of digital learning tools, arranging webinars and creation of 
national learning platforms (Chandra, 2020). In the U.S., for instance, the growing number of COVID-19 cases across nation has led to a decision by university administrators to move classes to virtual environments for the remainder of the spring 2020 semester and, in most cases, for the summer 2020 semester. It should be noted, however, that many of the instructors had little to no experience of teaching remotely and struggled to find ways to meet the learning needs of all students as they were faced with the unenviable task of quickly reorganizing their on-site classes so that content could be delivered online (Munsell, O'Malley, \& Mackey, 2020). Similarly, in Indonesia, the implementation of the Covid-19 emergency began in mid-March 2020 and was characterized by a "lockdown" that lasted for several months, but the state was declared in August 2020 in the form of a new normal, or new normal era. The impact of online education in this new normal era on students' ability to express their opinions, to answer questions, to ask questions, and to submit rebuttals is a great concern (Sudiyono, 2021).

For these problems we face, online collaborative learning seems to point in the direction of one solution. It was hoped that the crisis would force educational institutions that had been reluctant to change to embrace modern technology (Dhawan, 2020). Researchers have long highlighted the importance of collaborative learning (Ghavifekr, 2020; Saqr, Fors, \& Tedre, 2018), and adding the online component increased interest in online collaborative learning.

Collaborative learning is said to develop students' social interaction skills, encourage reflection, diversify understanding, and stimulate critical and higher-order thinking skills (Ghavifekr, 2020), and online learning can make teaching and process more student centered, more innovative, and more flexible. Online learning is defined as learning that takes place in a synchronous or asynchronous environment using a variety of Internet-connected devices, and it allows students to learn independently from anywhere; it also promotes broad interactions with teachers and other students (Singh \& Thurman, 2019).

Combining collaborative and online learning fosters relationships and a sense of community among learners and allows active and close monitoring group activities (Brindley, 2009). However, the problem with online collaborative learning is that adding collaboration, which is supposed to allow for flexible time management, negatively 
affects online learning's advantages of flexibility and convenience (Chiong \& Jovanovic, 2012). Muuro, Wagacha, Kihoro, and Oboko (2014) discussed a number of drawbacks to online collaborative learning, such as low student participation and lack of effective feedback from the teacher, and Dhawan (2020) and Faize and Nawaz (2020) observed that the time flexibility with online learning could in fact be a disadvantage for actual student learning.

\section{Table 1 Students' Internet Capacities}

As of April 23, 2020

\begin{tabular}{lll} 
Device Type & Number & Percentage \\
\hline Smartphone Only & 126 & $27 \%$ \\
Tablet Only & 15 & $3 \%$ \\
PC Only & 27 & $6 \%$ \\
Smartphone, Tablet & 52 & $11 \%$ \\
Smartphone, PC & 153 & $33 \%$ \\
Tablet, PC & 13 & $3 \%$ \\
Smartphone, Tablet, PC & 77 & $17 \%$ \\
Others (Play Station) & 1 & $0 \%$
\end{tabular}

\begin{tabular}{lcc} 
Can you browse websites? & number & percentage \\
\hline Yes & 460 & $99 \%$ \\
No & 4 & $1 \%$
\end{tabular}

\begin{tabular}{lcc} 
Can you watch YouTube videos? & number & percentage \\
\hline Yes & 456 & $98 \%$ \\
No & 8 & $2 \%$
\end{tabular}

Can you use Microsoft Office? number percentage 


\begin{tabular}{lll}
\hline Yes & 387 & $83 \%$ \\
No & 77 & $17 \%$ \\
Can you send email? & & \\
\hline Yes & number & percentage \\
No & 458 & $99 \%$ \\
& 6 & $1 \%$ \\
Can you send attached files via email? & number & percentage \\
\hline Yes & 372 & $80 \%$ \\
No & 86 & $19 \%$ \\
null & 6 & $1 \%$
\end{tabular}

Our response in the English department to this online education trend was to create our own video clips explaining English grammar and composition and upload them to a limited YouTube channel. We had to use a one-way distribution channel rather than a real-time interactive channel such as Zoom because it turned out that not all of our students had access to Internet-capable devices. We conducted a survey of our students $(\mathrm{n}=464)$ right after the closure (April 23, 2020) to measure their Internet and device capability, and Table 1 shows that around a quarter of students only had a smartphone; moreover, the school building lacked Wi-Fi capacity. These realities kept us from incorporating real-time online collaborative learning as a standard learning method in our school, and we observed the case to be similar at neighboring schools. As is stated above, online collaborative learning would be a very attractive prospect for the future, but it requires broader infrastructure, which is not currently in place at our school, and thus it could not be adopted uniformly. We ended the year 2020 still struggling with how to provide students with collaborative learning opportunities within the constraints of the current infection prevention measures, which restrict physical contact among the students. 


\section{THE CLASS OF 2020}

\section{Research Hypothesis and Issues}

Because of COVID-19, many of the activities we had taken for granted were prohibited for the students in 2020. Instead, we were forced to hold classes under strange constraints that restricted how we could teach. However, one thing our year of COVID learning offered was the opportunity to reflect on what is essential in teaching and learning by examining how the year's constraints and limitations had affected our students' learning. Until this time, we had never explored what helped make our teaching efforts successful.

So what did we assume was the most important thing we lost in 2020? Put simply, collaboration: the students' sense that they had peers they could learn with and we teachers' certainty that learning is a collaborative process. This was the hypothesis we developed, and we set out to test it by answering the following research question:

RQ1: How did students evaluate their year of learning under the 2020 COVID-19 pandemic conditions that severely restricted contact and collaboration?

The significance of analyzing the special year of 2020 was that because we lacked so much of what we took for granted, we could examine aspects of class that we had not paid much attention to during normal times. The disaster gave us a golden opportunity to (1) understand what is intrinsically important to student learning irrespective of particular circumstances, (2) reflect on what we as teachers should have provided to our students during the COVID-19 pandemic disaster, and (3) think beforehand about what we should focus on to help our students learn under future unusual circumstances. In Hegelian terms, the "universal" is limited to the "particular" to reveal its universality more clearly (Kanaya, 2014: 48). In other words, we reveal the universal values in particular events and then adapt them to future individual cases.

\section{RESEARCH DESIGN}

According to Burns (2009), the main purpose of action research (AR) is "to find out more about what is going on in your own local context in order to change or improve current practice in that situation" (p. 115). The benefits of AR are that it encourages thinking systematically about what is currently happening and taking action if there is potential to improve practice (Kemmis \& McTaggart cited in Burns, 2005). Specifically, 
by analyzing our students' impressions of the special situation of the 2020 class, this study identified what was lost (or not lost) from the regular classes and what is of vital importance to our students and us teachers. Then, we examined how we can improve our classes in 2021.

\section{RESEARCH SUBJECTS}

For this study, we worked with two classes of 40 students who were in their first year at school in the 2020 school year ( $n=68$ valid responses).

\section{METHOD}

In March 2020, after the end-of-year examinations, we asked students to write their impressions of the class of 2020 on A4 paper. I used the KH coder (Higuchi, 2014) to analyze their responses and added items such as gender and their end-of-year grades. Grades are administered on a 5-point scale with 5 being the highest. The specific question was as follows; Please write about your impressions of the class in the past year, including requests and reflections.

\section{RESULTS}

Table 2 Common Words in the Students' Responses by Frequency of Occurrence

\begin{tabular}{|c|c|c|c|}
\hline extracted word & $\begin{array}{l}\text { number of } \\
\text { appearances }\end{array}$ & extracted word & $\begin{array}{l}\text { number } \\
\text { appearances }\end{array}$ \\
\hline word & 101 & communication & 8 \\
\hline grammar & 40 & feel & 8 \\
\hline lesson & 38 & get & 8 \\
\hline test & 37 & take & 8 \\
\hline memorize & 36 & write & 8 \\
\hline long passage & 34 & readable & 8 \\
\hline listening & 30 & content & 8 \\
\hline ability & 23 & enter & 8 \\
\hline study & 22 & sentence & 8 \\
\hline increase & 18 & composition & 7 \\
\hline mock exam & 18 & not at all & 7 \\
\hline poor & 16 & with a little & 6 \\
\hline
\end{tabular}


|Volume 6 |Number 2 |December 2021 |E-ISSN: 2503-4405 |P-ISSN: 2580-3441 |

\begin{tabular}{|c|c|c|}
\hline read & 16 & meaning \\
\hline score & 14 & home \\
\hline myself & 13 & learning \\
\hline a lot & 13 & try \\
\hline junior nigh & 13 & high school \\
\hline passage & 13 & appear \\
\hline understand & 13 & self \\
\hline see & 12 & build \\
\hline time & 12 & group \\
\hline prior & 11 & COVID-19 \\
\hline hear & 11 & activity \\
\hline speaking & 10 & opportunity \\
\hline read aloud & 10 & vocabulary \\
\hline learn & 10 & structure \\
\hline reading & 10 & now \\
\hline plenty & 9 & this year \\
\hline question & 9 & use \\
\hline \multirow[t]{12}{*}{ speaking } & 9 & idiom \\
\hline & & able \\
\hline & & enough \\
\hline & & low \\
\hline & & regular test \\
\hline & & mind \\
\hline & & difficult \\
\hline & & review \\
\hline & & comprehend \\
\hline & & forget \\
\hline & & fail \\
\hline & & practice \\
\hline
\end{tabular}


Table 3 Common Words in the Students' Responses by End-of-Year Grade

$\begin{array}{lcllllllll}2 & & & & & & & & & \\ \end{array}$

My content analysis included extracting words that appeared commonly across the students' questionnaire responses. I identified 5827 distinct words and 802 that overlapped across responses; Table 2 shows that the two most commonly used words were "word" and "grammar," indicating that the students' interests generally revolved around the weekly vocabulary and grammar quizzes. However, Table 3 and Figure 1 illustrate the word frequencies according to the students' end-of-year grades, and the table indicates that the highest performers, especially those with a grade of 5 , were more interested in the oral aspect of English learning, namely speaking and listening. This finding suggests that the top-level students were less concerned with their performance on the weekly quizzes and more focused on learning English outside of the class setting, and this was especially true for students with some confidence in reading and writing. 


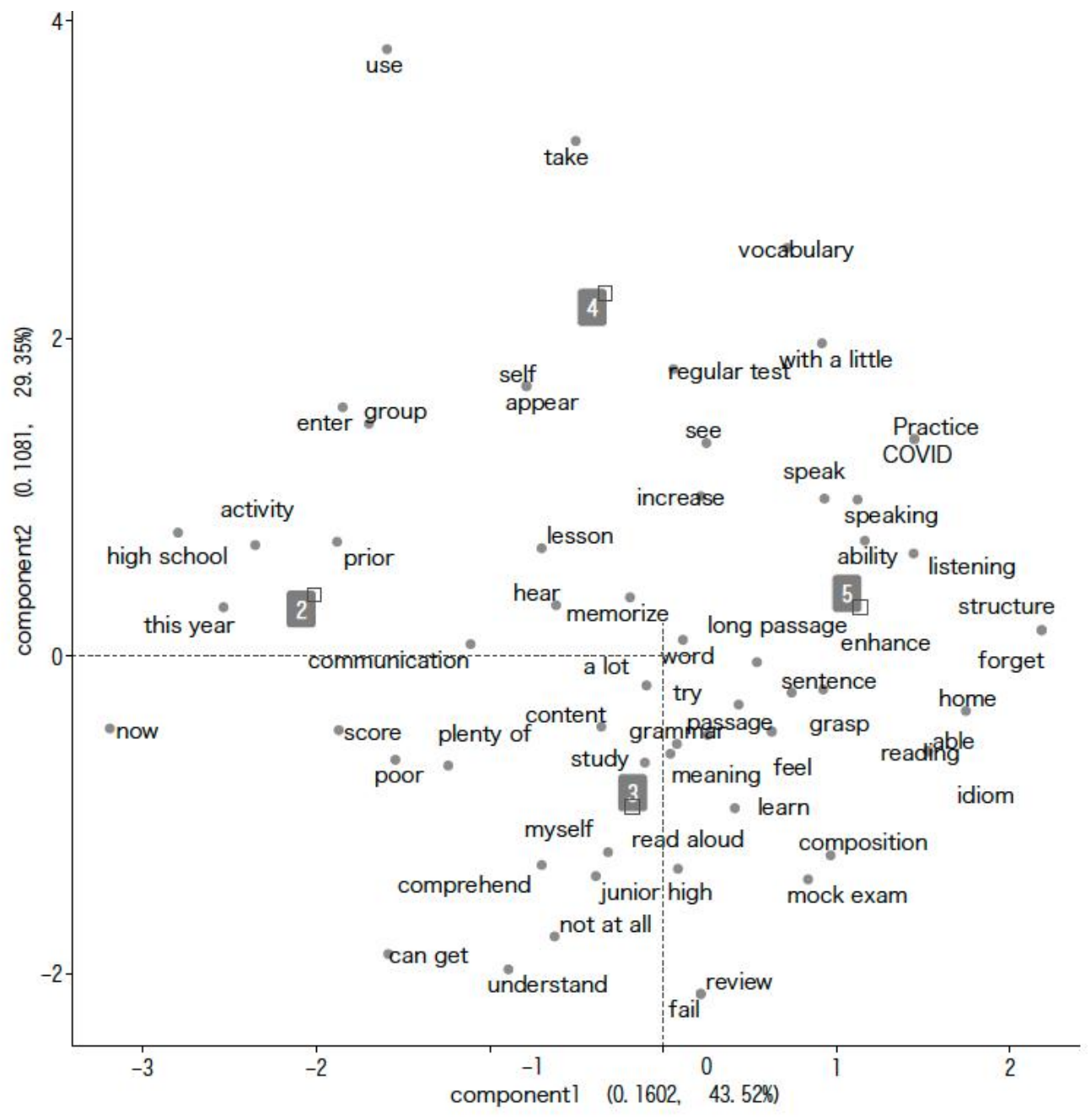

Figure 1. Correspondence analysis by end-of-year grade.

I also identified that students who had ended the year with a grade of 2 commonly used the words "activity" and "group." This finding seemed to suggest that the poorerperforming students had difficulty learning on their own or determining the meaning of their own learning and were not motivated to learn without opportunities for collaboration, such as exchanging opinions with others and presenting to others. Statistically, there was no gender difference in this result. Figure 2 displays the cooccurrence network that resulted from our analysis. 


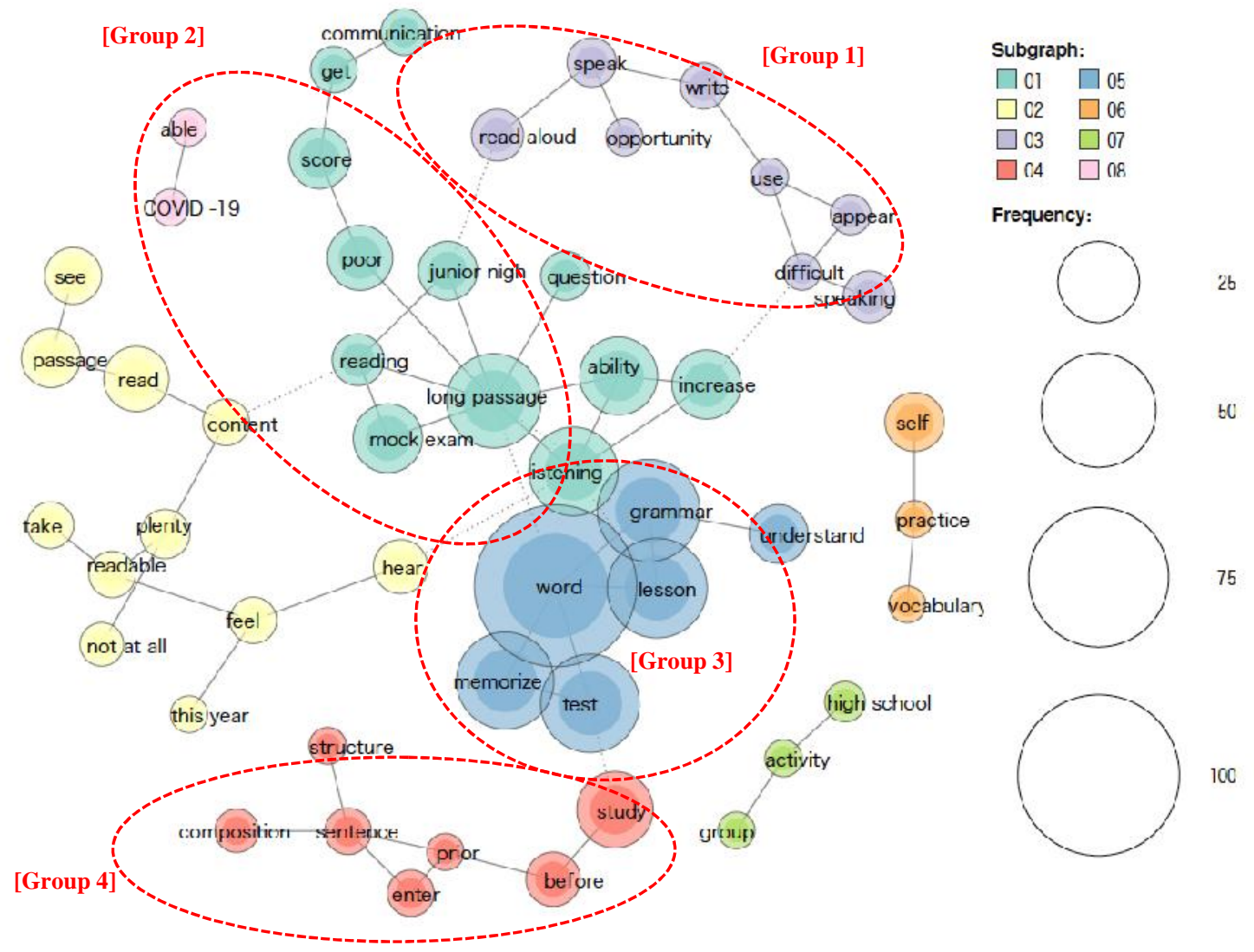

Figure 2. Word frequency co-occurrence network.

The network displays that we could group the frequently used words by themes, which I color-coded for the network. Group 1 words (purple in the figure) related to speech-centered activities, and this group was characterized by students who felt difficulty speaking English or were reluctant to do so because they had very few opportunities to read aloud or speak.

The words in groups 2 (green) and 3 (blue) related to the big test and the weekly quizzes, respectively. The students who frequently used these words wanted to improve their reading and listening skills and their quiz and exam scores; their classroom concerns, reflected in their repeated use of "word" and "grammar," were tied to their performance on the weekly vocabulary and grammar quizzes. These findings clearly reflect how the class of 2020 was dominated by knowledge-based teaching and testing.

The group 4 words (red) related to writing, and very few students wrote about writing. In 2020, the students had no opportunities to write in English except for the grammar exercises, and they were given virtually no opportunities to write their own 
opinions, for instance in essays. The students still expected to be able to speak fluently as they had in junior high school, but they were less aware of writing skills than they should have been.

My findings gave the following answer to RQ1: For the class of 2020, we were only able to arouse interest in the weekly vocabulary quizzes, regular examinations, and other paper tests, and at least some students were anxious about skills that could not be measured by paper tests. Below I discuss what we as teachers learned for ourselves and how we could operationalize these findings.

\section{DISCUSSION}

Now I turn to the significance of analyzing the class of 2020 specifically. First, these students started their school year in isolation, away from other students, and even after school reopened, they were deprived of opportunities to participate in pair work and group work and exchange knowledge and opinions with each other in class. In their own words, they lost the feeling of "friends are learning with me" and "I have time to tell someone something or have something to tell my friends about." As a result of COVID-19 restrictions, the students were deprived of the sense of belonging not only in terms of actively working with each other but even in just a semblance of the sense of just feeling seen and heard by others during their learning processes.

If it is the case that the students most missed collaboration, then my findings also clearly show what we as teachers should have provided to our students trying to learn under severe COVID restrictions. First, rather than devising efficient ways of communicating knowledge and skills (which is of course important), we should have asked ourselves how we could have created among our students a sense of learning together with friends during the period when the school was closed.

In turn, what we learned offered lessons for how to proceed in the next event of unusual circumstances. It is of primary importance for us teachers to create for the students the sense that their peers and friends are there for them to learn from both online and offline even if they are physically distant. In general, emotional well-being and the feeling of being supported by peers are associated with intrinsic motivation. Students who believe their peers support them and care about them are more likely to participate actively in class and school activities, pursue academic and social goals more 
frequently, and achieve higher grades than students who do not feel such support (Wentzel \& Watkins, 2002). Making students feel that someone is there and that they are not alone out of contact with others is critical to their success, especially in online learning (Stacey, 1999). In brief, the results of my analysis of how our students perceived the unusual situation of the 2020 school year reminded us teachers of the importance in learning of fostering even the loose sense of community and the critical impacts of its loss. Pandemic restrictions were still in place when the new school year began, so that we could take my findings and incorporate them into classroom teaching in the new year.

\section{THE CLASS IN 2021}

\section{Teaching Practice}

When the 2021 school year started, the aforementioned infection prevention guidelines were still in effect. I shared my findings with my colleagues, recognizing the negative impacts on learning of the lack of a loose sense of community and collaboration has on learning. We realize that we were not able to meet our students' needs in the classroom in the previous year, and we decided to revise some of our agreement. Specifically, at the beginning of the year, we decided to conduct some activities in pairs and groups on a trial basis to revive collaborative learning. We still had to pay maximum attention to the COVID-19 guidelines such as keeping physical distance, having students write rather than speak aloud, and other prevention measures. The following are the activities we initiated to reintroduce collaboration in the classroom:

(1) Jigsaw reading (reading aloud activity in pairs)

The teacher distributed sheets of different sections from the textbook blanked out so that student A and B had a communication gap, and the students had to read aloud to each other while recalling what they had learned.

(2) Essay writing

Students wrote essays on the theme of "What is the ideal diet for good health?" After they wrote their essays, they exchanged their work in groups, indicated parts they thought were well written, and returned each other's work with comments.

(3) Chain-letter writing

We gave the students the theme of "Is it good to use a smart phone in class?" for the 
chain-letter writing activity (Miura, Nakashima, \& Hiroyama, 2002). This paper-based dialogue activity follows steps a) to c) below:

a) The first person writes whether he or she agrees or disagrees with a controversial issue and ends the sentence with "What do you think?"

b) The second person always refutes the first person's opinion.

c) The third person reads the essays of the first two people and writes a judgment about which opinion he or she agrees with, along with reasons.

(4) Debate

Using the theme "Should schools introduce nap time?" groups of five students debated. Two argued for the affirmative, two argued for the negative, and one was the judge, and each group played the debate game from argument to rebuttal.

(5) Summary (Retelling)

Students worked in groups of four and were responsible for each part of one lesson in the textbook. They were asked to extract 5-10 key words from the text and summarize the texts in their own words based on the selected key words. The teacher instructed the listeners to give hints to the speaker when he or she was at a loss for words.

(6) Listening

Students practiced listening comprehension check once a week for 10 minutes using commercially available listening materials. Students checked their answers in pairs

\section{RESEARCH DESIGN}

Having identified what had been missing in 2020 and implemented new ideas in 2021 , we set out to answer the next research question based on the above experimental practices:

RQ2: How did the students evaluate the first semester of the 2021 school year with collaborative learning reintroduced? 


\section{RESEARCH SUBJECTS}

For accurate comparison, we selected as my subjects for analysis 40 second-year students from two classes $(n=79)$ who had experienced the COVID restrictions in their first year.

\section{METHOD}

In the last class of the first semester, we distributed to students a Google Forms document that asked them the following questions. Each teacher confirmed both orally and in writing that the questionnaire was anonymous and that the results would not affect the students' grades in any way.

\section{Questions}

Q1: Are you good at English? (5-point Likert scale: 1, very poor at English to 5, very good at English)

Q2: Do you like English? (5-point scale: 1, hate very much to 5, like very much)

Q3: Please select up to 3 interesting activities out of (1) to (6) that you did in class this year.

Q4: Describe freely why you found the activities you chose interesting.

Q5: Do you think this year's class was better than last year's class under the COVID19 restrictions? (5-point scale: 1, greatly deteriorated to 5, greatly improved)

\section{RESULTS AND DISCUSSION}

My one-way ANOVA of the Q3 responses showed no statistically significant differences in the activities selected by gender, proficiency level (high, middle, low; Figure 3), or opinion of English (Figure 4). 


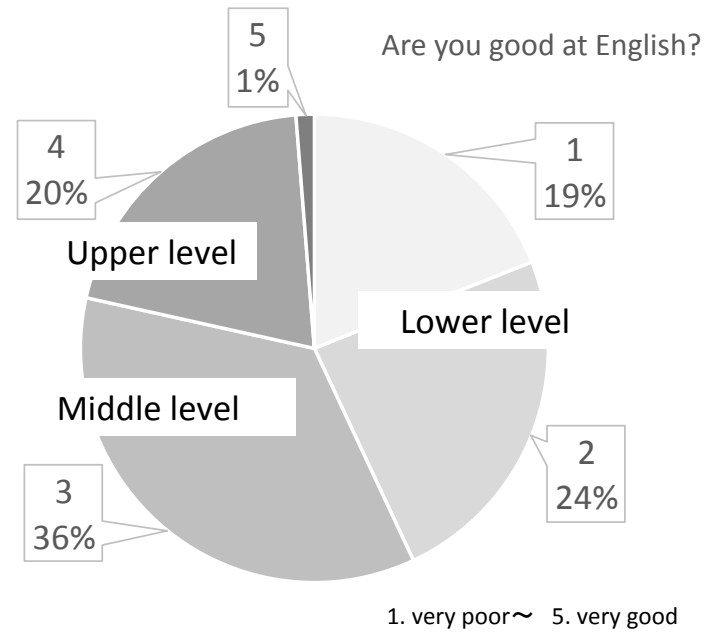

Figure 3. Students' English proficiency (self-assessment).

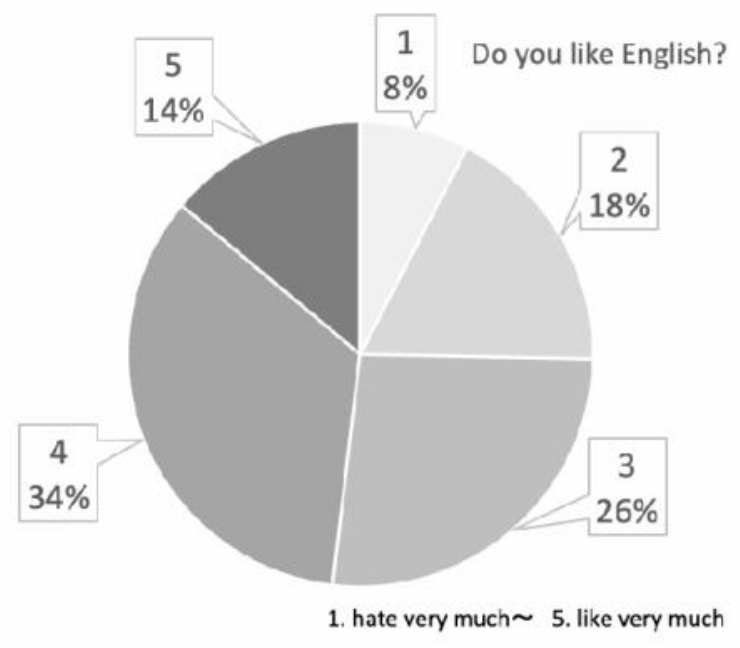

Figure 4. Students' opinions of English.

By number of responses (see Figure 5), the students found the debate activities the most interesting regardless of their grades. Cross-referencing the question responses, students who hated English very much responded that English writing activities (essay and chain-letter writing) were "the least difficult because I could think of activities by myself" and "it was fun to think while discussing with my friends." In contrast, students who liked English said that the debate activity was interesting because it "activated my brain" and "allowed me to test my English ability." It is also worth noting that some of the students who liked English wrote, "It is interesting to be able to use the knowledge and expressions I have" as a reason for preferring English composition. 


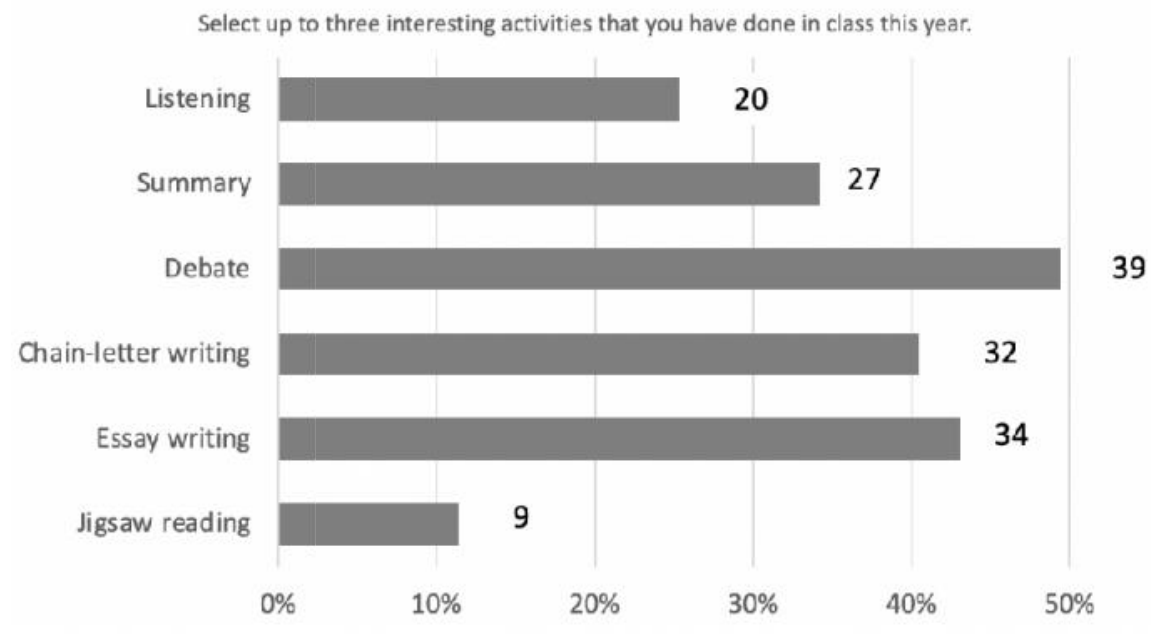

Figure 5. Students' three favorite in-class activities.

The students' interest in testing and grades seen in the 2020 survey seemed to have receded in the 2021 survey. For example, given the anxiety about listening seen in 2020, my colleagues and I expected that interest in listening activities would be high in 2021. However, there was little mention of listening in the free description answers; the students who liked English did not mention it at all, and those who disliked it were not good at it or were anxious about it. It was clear that the students' interests in the second year had shifted more to output than input activities.

In addition, a noticeable number of students reported finding the debate and retelling activities most interesting because they promoted understanding of the content and helped them prepare for tests ("it was useful," "I can learn," "it gives me strength"). Even when activities were related to knowledge retention, the students' interest increased when they worked together to actually transmit the information.

In the free descriptions, students made noticeably many references to collaborative learning. Some were very positive about the fact that they learned about other people's opinions through the debates and writing activities, and they even reported that their own opinions had deepened from having considered their classmates' perspectives. Students acknowledged the direct teacher feedback they received such as error correction, but they also highlighted the opportunities for self-reflection such as catching their own errors and indirectly organizing their knowledge by comparing their opinions with their classmates'. In addition, the classroom collaborations on the English essays increased the students' reflections on their own expression power (Yaacob \& Asraf, 
2021). Notably, we found this awareness across all groups irrespective of their opinions of English. My answer to RQ2 was that many students highly valued the deeper interactions in the various collaborative learning activities; they also particularly valued the opportunities to learn each other's opinions and broaden their own thoughts. Figure 6 shows that most students felt classes had improved in 2021 over the circumstances in 2020.

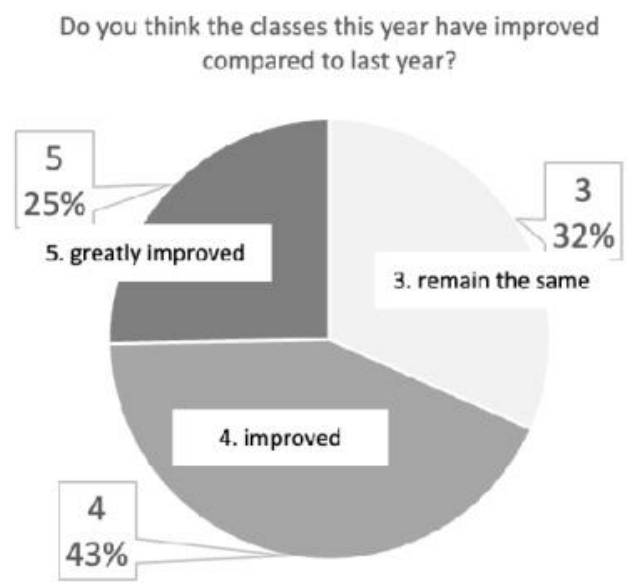

Figure 6. Students' evaluation of the class of 2021.

\section{CONCLUSION}

According to Myung and Kimner (2020), surviving turbulent VUCA environments requires sharing a set of "North Star" goals that will guide an organization. For the purposes of classroom instruction, my fellow teachers and I determined that our goals should be "student centered and ambitious" and "unchanging even under unstable and uncertain circumstances." From my analyses of the 2020 classes, we concluded that what is essential for a class even, or especially, under unstable and uncertain circumstances is recognizing the value of collaborative learning environments that foster the sense that students are not only watching and listening but being watched and listened to as they can feel other people's learning up close in the classroom. Pang et al. (2018) determined that creating the foundation for such an appropriate culture of collaborative learning requires paying close attention to students' daily communication practices, their discourses, the learning environment, and the classroom social structure. Research indicates that collaborative learning contributes significantly to improving students speaking skills (Pattanpichet, 2011). This is because practicing English in an authentic 
environment in which the target language is used for realistic purposes improves communicative skills and vocabulary knowledge (Avci \& Adiguzel, 2017).

The main contribution of this study is that for the first time, we have a clear picture of how the students felt about the various constraints in the classroom under the unprecedented circumstances of the 2020 COVID-19 pandemic and how they perceived the 2021 classes. In an AR study conducted in two school years, my colleagues and I administered questionnaires to our students to get their opinions, and I analyzed their responses to draw conclusions. It was clear from my findings that being able to feel "the presence of peers who learn from each other," a loose sense of community, increased students' motivation for learning; it was also clear that students strongly desired collaborative learning that fostered this loose sense of community. In other words, presented with clear findings of how collaboration is essential for improving and maintaining students' motivation to learn, we determined that irrespective of special circumstances such as a pandemic that requires rigorous infection prevention measures, it is crucial that we improve environments for collaborative learning whether online or offline. In terms of educational effectiveness, a future area of study could be how to quantitatively measure and verify the effects of collaborative learning on students' English proficiency.

\section{REFERENCES}

Avci, H., \& Adiguzel, T. (2017). A case study on mobile-blended collaborative learning in an English as a foreign language (EFL) context. International Review of Research in Open and Distributed Learning, 18(7). https://doi.org/10.19173/irrodl.v18i7.3261

Brindley, J. E., Blaschke, L. M., \& Walti, C. (2009). Creating effective collaborative learning groups in an online environment. International Review of Research in Open and Distributed Learning, 10(3). https://doi.org/10.19173/irrodl.v10i3.675

Burns, A. (2005). Action research: An evolving paradigm? Language Teaching, 38(2), 5774. https://doi.org/10.1017/S0261444805002661

Burns, A. (2009). Action research. In Qualitative research in applied linguistics Palgrave p. 112--134. Macmillan. 
Chandra, Y. (2020). Online education during COVID-19: perception of academic stress and emotional intelligence coping strategies among college students. Asian education and development studies, 10(2). 228-238.

Chiong, R., \& Jovanovic, J. (2012). Collaborative learning in online study groups: An evolutionary game theory perspective. Journal of Information Technology Education: Research. Informing Science Institute. Retrieved February 9, 2021. https://www.learntechlib.org/p/111494/, 11(1), 081-101. https://doi.org/10.28945/1574

Dhawan, S. (2020). Online learning: A panacea in the time of COVID-19 crisis. Journal of Educational Technology Systems, 49(1), 5-22.

Faize, F. \& Muhammad, N. (2020). Evaluation and Improvement of Students' Satisfaction in Online Learning during COVID-19. Open Praxis, 12(4), 495-507

Ghavifekr, S. (2020). Collaborative learning: A key to enhance students' social interaction skills. Malaysian Online Journal of Educational Sciences, 8(4), 9-21.

Higuchi, K. (2014). Quantitative text analysis for social research: Toward the succession and development of Content Analysis. Nakanishiya Publishing, Co.

Kanaya, Yoshihiro. (2014). The Logic of the Knife and the Spear: A Study of the Dialectical Identity of the Universal, the Particular, and the Individual. Bulletin of the Faculty of Education and Culture, Miyazaki University. Social Science, 30, 37-52. http://hdl.handle.net/10458/4820

Miura, T., Nakashima, Y., \& Hiroyama, S. (2002). So, so English is education: An approach to English teaching that nurtures the heart, Kenkyusha.

Munsell, S. E., O'Malley, L., \& Mackey, C. (2020). Coping with COVID. Educational Research: Theory and Practice, 31(3), 101-109.

Muuro, M. E., Wagacha, W. P., Kihoro, J., \& Oboko, R. (2014). Students' perceived challenges in an online collaborative learning environment: A case of higher learning institutions in Nairobi, Kenya. International Review of Research in Open and Distributed Learning, 15(6). https://doi.org/10.19173/irrodl.v15i6.1768

Myung, J., \& Kimner, H. (2020). Continuous improvement in schools in the COVID-19 context: A summary brief policy analysis for California education. PACE. 
Pang, C., Lau, J., Seah, C. P., Cheong, L., \& Low, A. (2018). Socially challenged collaborative learning of secondary school students in Singapore. Education Sciences, 8(1), 24. https://doi.org/10.3390/educsci8010024

Pattanpichet, F. (2011). The effects of using collaborative learning to enhance students English speaking achievement. Journal of College Teaching and Learning (TLC), 8(11), 1-10. https://doi.org/10.19030/tlc.v8i11.6502

Saqr, M., Fors, U., \& Tedre, M. (2018). How the study of online collaborative learning can guide teachers and predict students' performance in a medical course. BMC Medical Education, 18(1), 24. https://doi.org/10.1186/s12909-018-1126-1

Singh, V., \& Thurman, A. (2019). How many ways can we define online learning? A systematic literature review of definitions of online learning (1988--2018). American Journal of Distance Education, 33(4), 289-306. https://doi.org/10.1080/08923647.2019.1663082

Stacey, E. (1999). Collaborative learning in an online environment. Distance Education, 14(2), 14-33.

Sudiyono. (2021). Students Participation and Attendance in Following Lectures During Normal and Pandemic. English Education:Journal of English Teaching and Research, 6(1), 75-86. https://doi.org/10.29407/jetar.v6i1.15323

US Agency for International Development (2020). Education and COVID-19. https://files.eric.ed.gov/fulltext/ED612723.pdf

Wentzel, K. R., \& Watkins, D. E. (2002). Peer relationships and collaborative learning as contexts for academic enablers. School Psychology Review, 31(3), 366--377.

Yaacob, A., \& Asraf, M. (2021). Empowering learners' reflective thinking through collaborative reflective learning. International Journal of Instruction, 14(1), 709-726. 